\section{Willingness and professional motivations of medical students to work in rural areas: a study in Alexandria, Egypt}

\author{
Aida M. Mohamed \\ Community Medicine Department, \\ Faculty of Medicine, Alexandria \\ University, Egypt
}

\section{Abstract}

Retaining health workers in rural areas is challenging for a number of reasons, e.g. personal preferences, difficult work conditions and low remuneration. Our aim was to determine the effect of motivational factors on willingness to accept postings to rural underserved areas in Alexandria, Egypt and to identify perceived attributes of rural service.,A cross-sectional survey involving $3024^{\text {th }}$-year medical students was conducted in March-July 2012. Logistic regression analysis was used to assess the association between students' willingness to accept rural postings and their professional motivations, rural exposure and family parental professional and educational status (PPES). Perceived attributes to rural service were also assessed. Over $85 \%$ students were born in urban areas and $41.4 \%$ came from affluent backgrounds. More than half students reported strong intrinsic motivation to study medicine. After controlling for demographic characteristics and rural exposure, motivational factors significantly influenced willingness to practice in rural areas. High-family PPES was consistently associated with lower willingness to work in rural areas. A sizable portion of medical students are motivated to study and practice medicine in rural areas. Efforts should be made to build on motivation during medical training and designing rural postings, as well as favor lower PPES students for admission and improving organizational and contextual issues of rural service.

\section{Introduction}

The World Health Organization (WHO) estimates that more than 4 million health workers are needed to fill the health workforce gap globally. ${ }^{1}$ This includes 2.4 million physicians, nurses and midwives. Fifty-seven countries are defined as having a critical shortage of health staff; of these, 36 are in Sub-Saharan Africa. Medical services in Egypt greatly suffer shortage of healthcare workers; however, sta- tistics from Egypt concerning this is lacking. Africa has only $3 \%$ of the the total world's health work force (59.2 million people), in spite of having $25 \%$ of the global burden of disease. ${ }^{1,2}$

The shortage of health staff cripples the health delivery system. It is also a threat to provision of essential, life-saving interventions such as childhood immunizations, provision of safe water, safe pregnancy and childbirth services for mothers as well as access to treatment for AIDS, tuberculosis and malaria. Health workers are critical to the global preparedness for and response to threats posed by emerging and epidemic-prone diseases. Different interventions have been tried to address these shortages. Four main downstream interventions have been implemented by developed and developing countries: financial incentives, provision of education opportunities, interventions supporting the work of health professionals and regulatory mechanisms, such as compulsory services in underserved areas. ${ }^{2}$

Health worker shortages in rural areas have been identified as one of the biggest challenges to the health sector and a barrier to reaching the country's health-related Millennium Development Goal targets. ${ }^{3}$ While the public sector has made considerable efforts to place doctors (and a variety of other health workers) in rural areas, issues like absenteeism, ghost doctors, and dual practice have compromized the effectiveness of this effort.

Retaining health staff in rural areas has proven extremely difficult as young professionals increasingly prefer urban postings and health systems do not reward rural service. ${ }^{4}$ Qualitative research has also shown the importance of healthcare providers' personal characteristics and value systems, such as religious beliefs and socio-political convictions, to their motivation towards rural practice. Emigration of skilled professionals to highincome countries is another barrier to adequate staffing of health facilities. ${ }^{5} \mathrm{~A}$ study in Ghana in 2006 on trainee physicians and nurses revealed that the majority had considered emigrating. More physicians (68\%) than nurses (57\%) considered emigration. ${ }^{6}$ These findings imply that achieving improvements in the health status of people living in low-income countries, and particularly, in rural areas, will be extremely difficult. ${ }^{7}$

This highly uneven distribution between urban and rural areas is rooted in the fact that cities offer better incomes (e.g. the potential for private practice), more opportunities for career progression, better infrastructure and more social amenities than rural areas. ${ }^{8}$ While previous research has looked at incentives and working conditions to promote uptake of rural posts, few studies have focused on motivation crowding and its effect on willingness to accept postings to rural area. Motivation
Correspondence: Aida M. Mohamed, Community Medicine Department, Faculty of Medicine, Alexandria University, Al-Khartom square, Alexandria, Egypt.

Tel./Fax: +203.12792.9039.

E-mail: aida_mohey@yahoo.com

Key words: health manpower, motivation, rural health services, Egypt.

Acknowledgments: I am greatly indebted and grateful to Alexandria medical students who made this study possible. They devoted some of their precious time in helping me to collect the data.

Contributions: the authors contributed equally.

Conflict of interests: the authors declare no potential conflict of interests.

Received for publication: 12 December 2012.

Revision received: 10 February 2013.

Accepted for publication: 16 February 2013.

This work is licensed under a Creative Commons Attribution 3.0 License (by-nc 3.0).

(C)Copyright A.M. Mohamed., 2013

Licensee PAGEPress, Italy

Healthcare in Low-resource Settings 2013; 1:e4 doi:10.4081/hls.2013.e4

crowding is the conflict between external factors (extrinsic), such as monetary incentives or punishments, and the underlying desire or willingness to work (intrinsic) in areas needed most. Students may have a mix of extrinsic and intrinsic motivations for studying medicine. ${ }^{9}$ Relatively little research has been conducted on effective strategies to promote rural practice, particularly in low-income countries. ${ }^{10}$ To tackle the uneven distribution of human resources for health, understanding the factors that motivate medical students to study and practice medicine and their willingness to accept postings to rural underserved area is essential.

This study was conducted to determine the effect of motivational factors on stated willingness to accept postings to rural underserved areas in Alexandria, Egypt and to identify perceived attributes of rural service.

\section{Materials and Methods}

\section{Study design, setting and target population}

This descriptive cross-sectional survey was conducted between March and July 2012 in the Alexandria Faculty of Medicine. Medical education consists of three years of basic sciences (BSc), and three years of clinical training at a 
teaching hospital in rotating housemanship. A stratified random sample of medical students was invited to participate in the study. Stratification is based on the clinical round rotations (4 groups in 4 clinical rounds of different departments). Fourth-year medical students were selected because they had completed the BSc, and had also been exposed to field work, but had not yet made their final decisions about rural or urban practice.

The total number of fourth year students was 960 . Sex distribution reflects that males $(n=576)$ outnumbered females $(n=384)$ (faculty registration year: 2012). With the assumption that students' willingness to work in rural areas was $30 \%$ and using a significant level of 0.05 , a sample size of 355 fourth-year Alexandria medical school was selected with equal proportionate to clinical round size $(\mathrm{n}=120)$, a sample of approximately 45 students from each clinical round $(n=8)$ was randomly enrolled.

\section{Data collection}

Data collection was preceded by approvals from the heads of the involved departments, who were informed of the content of the questionnaire and provided access to the student population. The data collection instruments were developed after three-focus group discussions of 6-8 participants facilitated by the trained investigator. The themes for the focus group discussion were motivation, willingness to work in deprived areas, and the influence of background characteristics on willingness to work in deprived areas. The survey instrument - which included structured questions - was then pre-tested and finalized for the study. The questionnaires were administered to the students in their clinical departments at the Faculty of Medicine. The survey format took 30 min to be filled on average.

The questionnaires covered the following domains.

i) Students were asked to rate how likely they were to work in a deprived area (at any time in their careers) on a scale from 1-4, where 1 represented I will definitely not work in a deprived area; 2 I am unlikely to work in a deprived area; 3 I am likely to work in a deprived area; and 4 I will definitely work in a deprived area. This response set was collapsed to a dichotomous willing (groups 3 or 4) vs unwilling (groups 1 or 2 ) to practice in a deprived area. Deprived area was defined as $a$ rural area that is distant from the big cities with few social amenities such as schools, roads, pipe-borne water, etc. ${ }^{2}$

ii) Students were also asked to identify any of the 12 factors (identified as important by the focus group discussions) that motivated them to study and practice medicine. The five intrinsic motivations included: desire to help others, desire to give back to their home community or country, interest in medicine as a subject matter, inspiration by a role model, and loss of a loved one. The seven extrinsic motivation factors included: income of physicians, job security and lifestyle, social status/prestige, proposed by parents, opportunities to travel and work internationally, ability to use new cutting-edge technologies, and research opportunities. Motivation factors were coded as no $=0$ and yes $=1$. Respondents were coded as having strong intrinsic or extrinsic motivation if total score was $\geq 3$. Thus, strong intrinsic and extrinsic motivation groups were mutually exclusive.

iii) Socio-demographic factors included: sex, age, marital status and parental professional and educational status (PPES). High PPES was defined as having a mother and/or father who is a university-trained professional (e.g. doctor, lawyer, engineer, accountant, technical, etc.) and low PPES was defined as having neither mother nor father as a universitytrained professional.

iv) Rural (an area with a population less than 5000) exposure factors included: birth location (urban $v s$ rural), having ever lived in rural area (from the age of 5 onwards), and exposure to rural service in medical training (for a minimum of 6 months).

v) The students were also asked to indicate the strength of a set of important organizational and contextual attributes and conditions for rural practice. These identified through a literature review and discussions with physicians from the Ministry of Health and practicing physicians.

\section{Ethical considerations}

The study received ethics approval from the Ethical Review Committee at the Alexandria Faculty of Medicine. All respondents voluntarily participated after the intent and design of the study were explained to them and signing informed consent forms. The study participants were assured of anonymity and confidentiality, in responding to the questions. Confidentiality of the data was maintained throughout the study.

\section{Statistical analysis}

The study used SPSS version 18.0 for data entry and statistical analyses. Descriptive statistics such as frequency, percentage, mean and standard deviation (SD) were conducted to describe socio-demographic characteristics and rural exposure as well as perceived attributes to rural service. Bivariate associations and $95 \%$ confidence intervals (CIs) were estimated using multivariate logistic regression analysis. The main outcome of interest was the willingness to work in a deprived area after graduation. Predictors of interest included motivation (intrinsic and extrinsic), demographic characteristics, and rural exposure variables. Significance was set at 0.05 level.

\section{Results}

\section{Socio-demographic characteristics}

\section{and rural exposure}

Of the 355 eligible medical students, 302 participated in the survey (85.0\% response rate). The socio-demographic characteristics of respondents are presented in Table 1. Of the 302 respondents recruited for the study, the majority were male $(60.6 \%)$, with a mean age of 20.9 (SD 1.4). Only $5.6 \%$ of them were married or engaged. Most respondents were born in or around urban areas (87.4\%) and had never lived in rural underserved area (75.8\%). In terms of socio-economic status, more than half of students (58.6\%) came from low PPES families and the rest (41.4\%) came from affluent backgrounds. About one fifth of the respondents (20.2\%) were exposed to rural service (rural outreach or service during medical studies).

\section{Professional motivation and likeli-} hood of working in an underserved area

Willingness to work in underserved area according to the intensities of current motivational factors is presented in Table 2 and Figure

Table 1. Socio-demographic characteristics and rural exposure of Alexandria medical students $(\mathrm{n}=302)$.

\begin{tabular}{|c|c|c|}
\hline Variable & & ncy \\
\hline & (n) & $\%$ \\
\hline Sex & & \\
\hline Male & 183 & 60.6 \\
\hline Female & 119 & 39.4 \\
\hline Age mean (SD) & $20.9(1.40$ & \\
\hline Family PPES & & \\
\hline Low $^{\circ}$ & 177 & 58.6 \\
\hline $\operatorname{High}^{\#}$ & 125 & 41.4 \\
\hline Marital status & & \\
\hline Married or engaged & 17 & 5.6 \\
\hline Not in a relationship & 285 & 94.4 \\
\hline Birth area & & \\
\hline Urban $^{\S}$ & 264 & 87.4 \\
\hline Rural $^{\wedge}$ & 38 & 12.6 \\
\hline Ever lived in rural areas & & \\
\hline Yes & 73 & 24.2 \\
\hline No & 229 & 75.8 \\
\hline Exposed to rural servic & & \\
\hline Yes & 61 & 20.2 \\
\hline No & 241 & 79.8 \\
\hline $\begin{array}{l}\text { SD, standard deviation; PPES, p } \\
\text { status. }{ }^{\circ} \text { Low-family PPES, neith } \\
\text { graduated professional; "high-fa } \\
\text { university-graduated professio } \\
\text { accountant, technical, etc.); }{ }^{4} \text { u } \\
\text { more than } 5000 \text { residents; }{ }^{\wedge} \text { rur } \\
\text { than } 5000 \text { residents; } \$ \text { from age } \\
\text { reach or service in a deprived a }\end{array}$ & $\begin{array}{l}\text { tal professio } \\
\text { nother nor fat } \\
\text { PPES, mothe } \\
\text { (e.g. doctor, } \\
\text { narea define } \\
\text { rea defined a } \\
\text { onwards; }{ }^{\circ \circ} \\
\text { during medic }\end{array}$ & $\begin{array}{l}\text { ducational } \\
\text { Iniversity- } \\
\text { father is a } \\
\text { engineer, } \\
\text { lace with } \\
\text { with less } \\
\text { ed in out- } \\
\text {. }\end{array}$ \\
\hline
\end{tabular}


1. Overall, 158 (52.3\%) students stated that they were likely to or definitely would work in an underserved area. More than half of students $(181,59.9 \%)$ had strong intrinsic motivation to study medicine. A significantly higher proportion of respondents who had strong intrinsic motivation (61.3\%) indicated willingness to work in a rural area, compared to those with weak intrinsic motivation (38.8\%) $\left(\chi^{2}=7.952\right.$, $\mathrm{P}=0.008)$. Significantly higher proportions of those motivated to study medicine by the desire to give back to their home community or country (64.0\%) were willing to work in an underserved area as compared to $36.0 \%$ who would not like to work in rural area $(\mathrm{P}=0.007)$. More than two-thirds of students $(203,67.2 \%)$ had strong extrinsic motivation to study medicine. The results were reversed for those with strong extrinsic motivation. A significantly lower proportion of respondents who had strong extrinsic motivation (35.0\%) indicated willingness to work in a rural area, compared to those with weak extrinsic motivation (87.9\%) $\left(\chi^{2}=8.121\right.$, $\mathrm{P}=0.003)$.

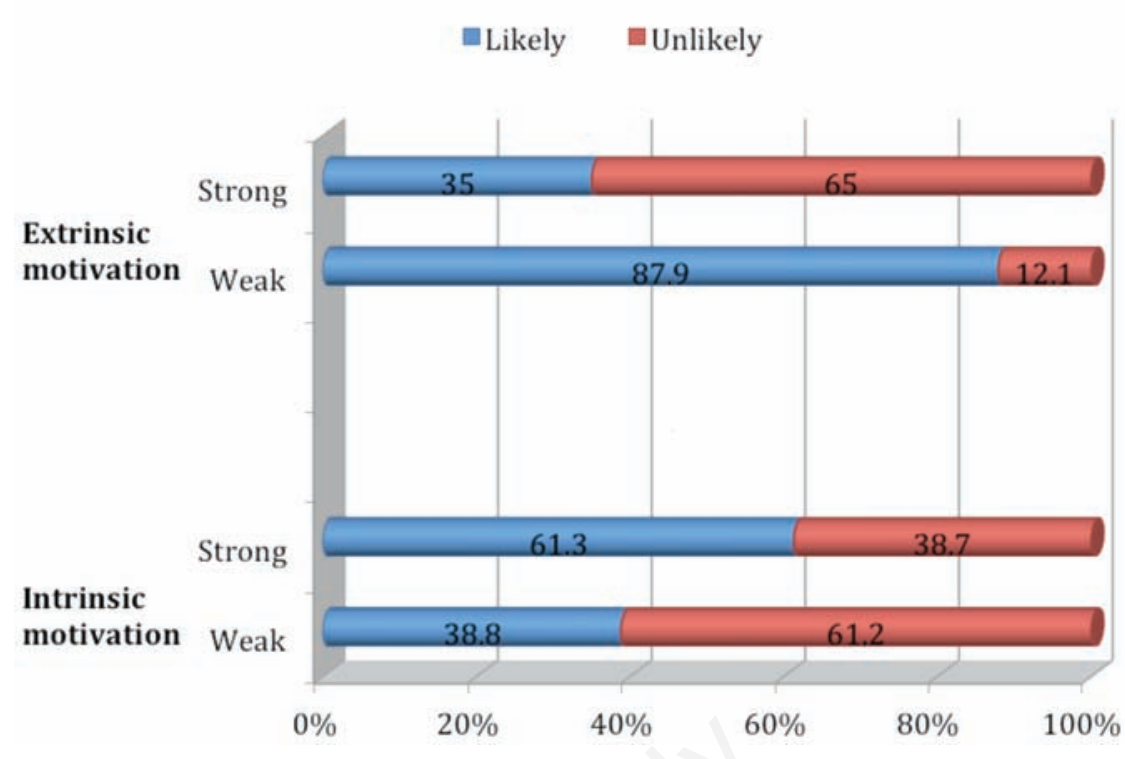

Figure 1. Willingness of Alexandria medical students $(n=302)$ to work in an underserved area according to strength of factors that motivated them to study medicine.

Table 2. Willingness and current motivations of Alexandria medical students $(n=302)$ to work in an underserved area according to factors that motivated them to study and practice medicine.

\begin{tabular}{|c|c|c|c|c|c|c|c|}
\hline \multirow{2}{*}{\multicolumn{2}{|c|}{$\begin{array}{l}\text { Factors motivating Alexandria medical } \\
\text { students to study and practice medicine }\end{array}$}} & \multirow[t]{3}{*}{ Total (n) } & \multicolumn{4}{|c|}{ Willingness to work in an underserved area } & \multirow[t]{3}{*}{$\begin{array}{l}\chi^{2} \text { test } \\
(\mathrm{P} \text { value })\end{array}$} \\
\hline & & & \multicolumn{2}{|c|}{ Unlikely } & \multicolumn{2}{|c|}{ Likely } & \\
\hline Domain & Items & & n & $\%$ & n & $\%$ & \\
\hline \multirow[t]{5}{*}{ Intrinsic motivation } & Desire to help others & 284 & 135 & 47.5 & 149 & 52.5 & $\begin{array}{c}3.764 \\
(0.836)\end{array}$ \\
\hline & $\begin{array}{l}\text { Desire to give back to their } \\
\text { home community or country }\end{array}$ & 114 & 41 & 36.0 & 73 & 64.0 & $\begin{array}{c}7.942 \\
(0.007)^{*}\end{array}$ \\
\hline & Interest in medicine as a subject matter & 118 & 62 & 52.5 & 56 & 47.5 & $\begin{array}{c}3.968 \\
(0.802)\end{array}$ \\
\hline & Inspiration by a role model & 84 & 60 & 71.4 & 24 & 28.6 & $\begin{array}{l}8.032 \\
(0.003)^{*}\end{array}$ \\
\hline & Loss of a loved one & 13 & 12 & 92.3 & 1 & 7.7 & $\mathrm{FE}(0.000) *$ \\
\hline Weak motivation ${ }^{\#}$ & & 121 & 74 & 61.2 & 47 & 38.8 & $\begin{array}{c}7.952 \\
(0.008)^{*}\end{array}$ \\
\hline Strong motivation ${ }^{\S}$ & $\sqrt{n+2}$ & 181 & 70 & 38.7 & 111 & 61.3 & $\begin{array}{c}7.952 \\
(0.008)^{*}\end{array}$ \\
\hline \multirow[t]{7}{*}{ Extrinsic motivation } & Income of physicians & 216 & 174 & 80.6 & 42 & 19.4 & $\begin{array}{l}7.523 \\
(0.009)^{*}\end{array}$ \\
\hline & Job security and lifestyle & 119 & 76 & 63.9 & 43 & 36.1 & $\begin{array}{c}6.236 \\
(0.028)^{*}\end{array}$ \\
\hline & Social status/prestige & 212 & 192 & 90.6 & 20 & 9.4 & $\begin{array}{c}9.612 \\
(0.000)^{*}\end{array}$ \\
\hline & Proposed by parents & 59 & 32 & 54.2 & 27 & 45.8 & $\begin{array}{l}2.754 \\
(0.814)\end{array}$ \\
\hline & Opportunities to travel and work internationally & 181 & 112 & 61.9 & 69 & 38.1 & $\begin{array}{c}6.034 \\
(0.033)^{*}\end{array}$ \\
\hline & Ability to use new cutting-edge technologies & 109 & 100 & 91.7 & 9 & 8.3 & $\begin{array}{c}8.632 \\
(0.002)^{*}\end{array}$ \\
\hline & Research opportunities & 23 & 22 & 95.7 & 1 & 4.3 & $\mathrm{FE}(0.000)^{*}$ \\
\hline Weak motivation ${ }^{\#}$ & & 99 & 12 & 12.1 & 87 & 87.9 & $\begin{array}{c}8.121 \\
(0.003)^{*}\end{array}$ \\
\hline Strong motivation ${ }^{\S}$ & 203 & 132 & $65.0 \quad 71$ & 35.0 & & & \\
\hline Total & 302 & 144 & $47.7 \quad 158$ & 52.3 & - & & \\
\hline
\end{tabular}




\section{Multivariate analysis of motivations} and the willingness to accept postings in a rural underserved area after graduation

Multivariate logistic regression results for strength of intrinsic motivation and willingness to work in a rural underserved area after graduation are presented in Table 3. Variables included in the model were those significantly associated with willingness to work in a deprived area by bivariate analysis. In the final adjusted model, having a strong intrinsic motivation increased the odds of being willing to accept a job in an underserved area [adjusted odds ratio $(\mathrm{AOR})=2.6,95 \% \mathrm{CI} 1.3-8.2]$. In the model adjusting for demographics, high PPES were associated with reduced willingness to practice in underserved areas ( $\mathrm{AOR}=0.4,95 \%$ CI 0.2-0.8). While a higher age was associated with greater willingness to practice in a rural area (AOR=3.1, 95\% CI 1.8-7.5). Living in a rural area was significantly associated with greater willingness to practice in a rural area (AOR=3.2, 95\% CI 1.8-7.4). These variables constituted $80 \%$ of factors influencing the willing to work in a deprived area $\left(\mathrm{R}^{2}=0.798\right)$ with an overall model (Likelihood ratio $\chi^{2}=33.48$, $\mathrm{P}=0.000$ ).

Table 4 shows the multivariate logistic regression results for the strength of extrinsic motivation and willingness to work in a rural underserved area after graduation. Variables included in the model were those significantly associated with willingness to work in a deprived area by bivariate analysis. In the final adjusted model, a strong extrinsic motivation reduced the odds of being willing to accept a job in an underserved area (AOR=0.5, 95\% CI 0.3-0.9). Demographic factors, female gender (AOR=0.4, 95\% CI 0.3-0.8), and high PPES (AOR=0.4, 95\% CI 0.2-0.7) were associated with reduced willingness to practice in a deprived area while a higher age was associated with greater willingness to practice in a rural area (AOR=3.8, 95\% CI 1.9-8.4). Living in a rural area was significantly associated with greater willingness to practice in a rural area (AOR=3.4, 95\% CI 1.7-7.0). These variables constituted $83 \%$ of factors influencing the willing to work in a deprived area $\left(\mathrm{R}^{2}=0.826\right)$ with an overall model (Likelihood ratio $\chi^{2}=31.33$, $\mathrm{P}=0.000$ ).

\section{Perceived attributes of rural service}

Table 5 shows students' perceived organizational and contextual factors pertaining to living in a rural area.

\section{Organizational factors}

\section{Financial attributes}

The vast majority of students (96.7\%) felt that a substantially higher salary is a strong attribute if they are to take up a rural job.

\section{Facilities}

One of the strong issues that medical students have with working in a rural area is the availability of infrastructure (staff, drugs, equipment, diagnostics, and physical structure of the health center) to treat patients: this was felt by $69.5 \%$ of students. Moreover, a good physical work environment (e.g. clean surroundings, good furniture) and having mentors were perceived to be important attributes by $65.6 \%$ and $62.9 \%$ of students, respectively.

\section{Organizational culture, policies and management}

Many students expressed their need for having clarity in the process for taking leave (60.3\%), and transfer policies (59.6\%).

\section{Career growth opportunities}

The vast majority of medical students (93.7\%) aspire to further specialize. Lower proportions felt that following graduation they were inadequately learned or trained to treat patients. The need for learning opportunities was perceived by $66.2 \%$ and for training opportunities by $65.6 \%$.

\section{Contextual factors}

Expectedly living facilities (housing, electricity, water, access to the market, hygiene) are felt as a strong attribute by almost the entire number of students except two (99.3\%). Moreover, a lower proportion (71.9\%) felt the need for security (physical security, legal protection against political interference).

Table 3. Multivariate logistic regression analysis of strength of intrinsic motivation and the willingness of Alexandria medical students $(n=302)$ to accept postings to rural underserved area after graduation.

\begin{tabular}{|c|c|c|c|}
\hline \multirow[t]{2}{*}{ Independent variables } & \multicolumn{3}{|c|}{$\begin{array}{l}\text { Willingness to accept postings } \\
\text { to rural underserved area after graduation }\end{array}$} \\
\hline & OR & CI & P value \\
\hline Strong intrinsic motivation to study medicine & 2.6 & $1.3-8.2$ & $0.001^{*}$ \\
\hline $\begin{array}{l}\text { Socio-demographics } \\
\text { Female } \\
\text { Age (years) } \\
\text { High-family PPES }\end{array}$ & $\begin{array}{l}0.5 \\
3.1 \\
0.4\end{array}$ & $\begin{array}{l}0.3-1.09 \\
1.8-7.5 \\
0.2-0.8\end{array}$ & $\begin{array}{c}0.634 \\
0.000^{*} \\
0.011^{*}\end{array}$ \\
\hline $\begin{array}{l}\text { Married or in a relationship } \\
\text { Rural exposure } \\
\text { Born in a rural area } \\
\text { Lived in a rural area } \\
\text { Exposed to rural service }\end{array}$ & $\begin{array}{l}1.4 \\
3.2 \\
1.5\end{array}$ & $\begin{array}{l}0.5-1.7 \\
0.5-4.3 \\
1.8-7.4 \\
0.8-2.8\end{array}$ & $\begin{array}{c}0.321 \\
0.009 * \\
0.467\end{array}$ \\
\hline $\mathrm{R}^{2}$ & 0.798 & & \\
\hline
\end{tabular}

Likelihood ratio $\chi^{2}, \mathrm{P}$

$33.48, \mathrm{P}=0.000^{*}$

$\mathrm{OR}$, odds ratio; CI, confidence interval; PPES, parental professional and educational status. ${ }^{\circ}$ High-family PPES, mother and/or father is a university-graduated professional (e.g. doctor, lawyer, engineer, accountant, technical, etc.).

Table 4. Multivariate logistic regression analysis of strength of extrinsic motivation and the willingness of Alexandria medical students $(n=302)$ to accept postings to rural underserved area after graduation.

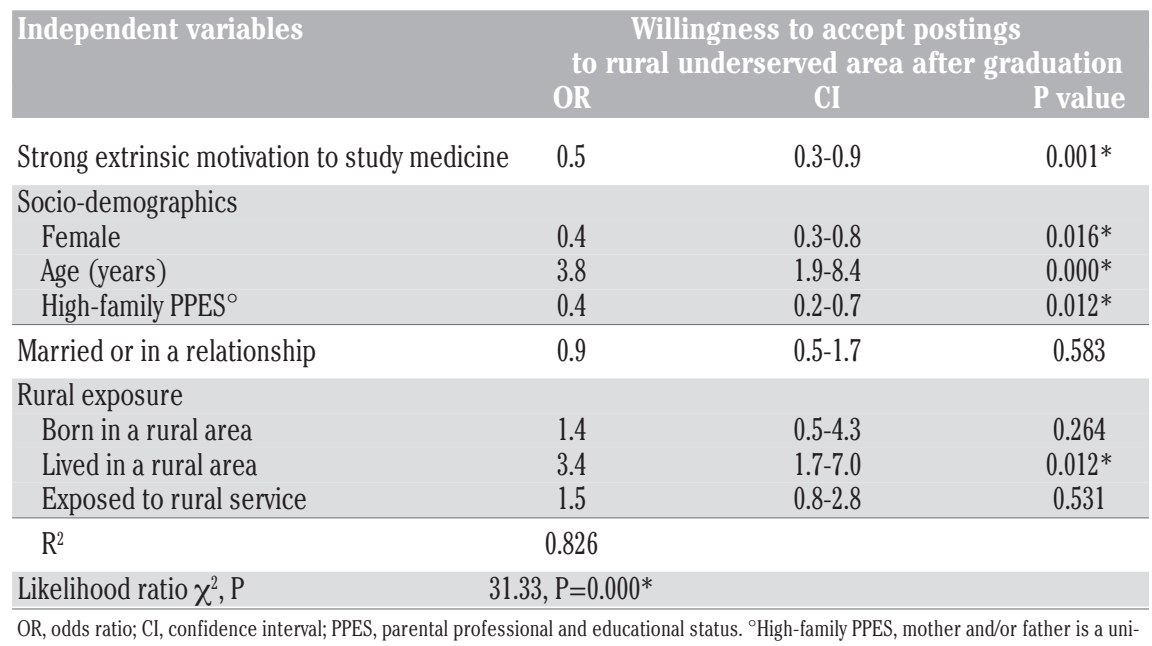
versity-graduated professional (e.g. doctor, lawyer, engineer, accountant, technical, etc.). 
Connectivity (transport availability, no sense of isolation) is expressed by $69.9 \%$ of students.

\section{Discussion}

The present study found that more students reported strong intrinsic motivation compared to high extrinsic motivation to study medicine. This may reflect the underlying altruistic motivation for many students entering a profession focused on serving others. ${ }^{6,7}$ Moreover, despite the fact that study participants were assured of anonymity and confidentiality in responding to the questions, there may also be an element of social desirability bias in the students' responses as intrinsic motivation may be thought to be more socially acceptable than extrinsic motivation. For this reason, a measure of high intrinsic and extrinsic motivation was selected for use in the regression models. Research comparing students stated intentions with their actual career choices during internship is urgently needed as few studies on matched follow-ups are available. In addition, most students participating in the study were young and had not yet tasted the rigors of working in a rural area, which may have affect- ed their job preferences. Thus, the findings of this study may not be applicable to practicing physicians. From the work of Serneels ${ }^{11}$ and Hanson, ${ }^{12}$ it appears that these two groups may differ in their preferences for rural practice.

In this study, a strong extrinsic motivation was associated with reduced reported willing for rural practice and the reverse was true for high intrinsic motivation. Similar results were reported in other studies. ${ }^{13,14}$ Interestingly, this association remained statistically significant at the $95 \% \mathrm{CI}$ in models with demographic and rural exposure confounders.

Studies conducted outside Egypt have found rural origin to be an important motivator for rural practice..$^{15-17}$ In contrast to this, the present study found that rural origin did not influence students' willingness to work in rural areas after controlling for intrinsic/extrinsic motivation and demographic characteristics. The difference could be due to the socio-cultural differences between different locations. This study highlights the importance of locallyrelevant data for decision making.

High socio-economic status, measured using parental education and profession, was consistently associated with lack of willingness to work in rural areas. This finding suggests that admission policies favoring well-to- do applicants may reduce the pool of students willing to consider rural practice.

Female gender was also strongly associated with reduced interest in rural practice for women even after controlling for extrinsic motivation and rural exposure variables. This is consistent with similar studies which revealed that women are less likely to accept positions in remote areas due to varying family reasons; they would like to live where their husbands' jobs are, have difficulties convincing their husbands to follow them to rural areas and want their children to have better education in urban areas. ${ }^{18-20}$ The studies further explained that female doctors rarely live in the same village as their assigned post and have higher overall absentee rates in rural practice. ${ }^{20,21}$ With increasing representation of female healthcare professionals, ${ }^{18}$ it is likely that the supply of health staff to rural underserved areas will remain a major setback if professional motivations are designed to attract more female students to rural practice. More research is urgently needed to determine how female healthcare professionals' motivations towards rural practice can be better engaged by policy-makers.

The present study examined the perceived factors that encourage graduates to work in a

Table 5. Perceived attributes of rural service by Alexandria medical students $(n=302)$.

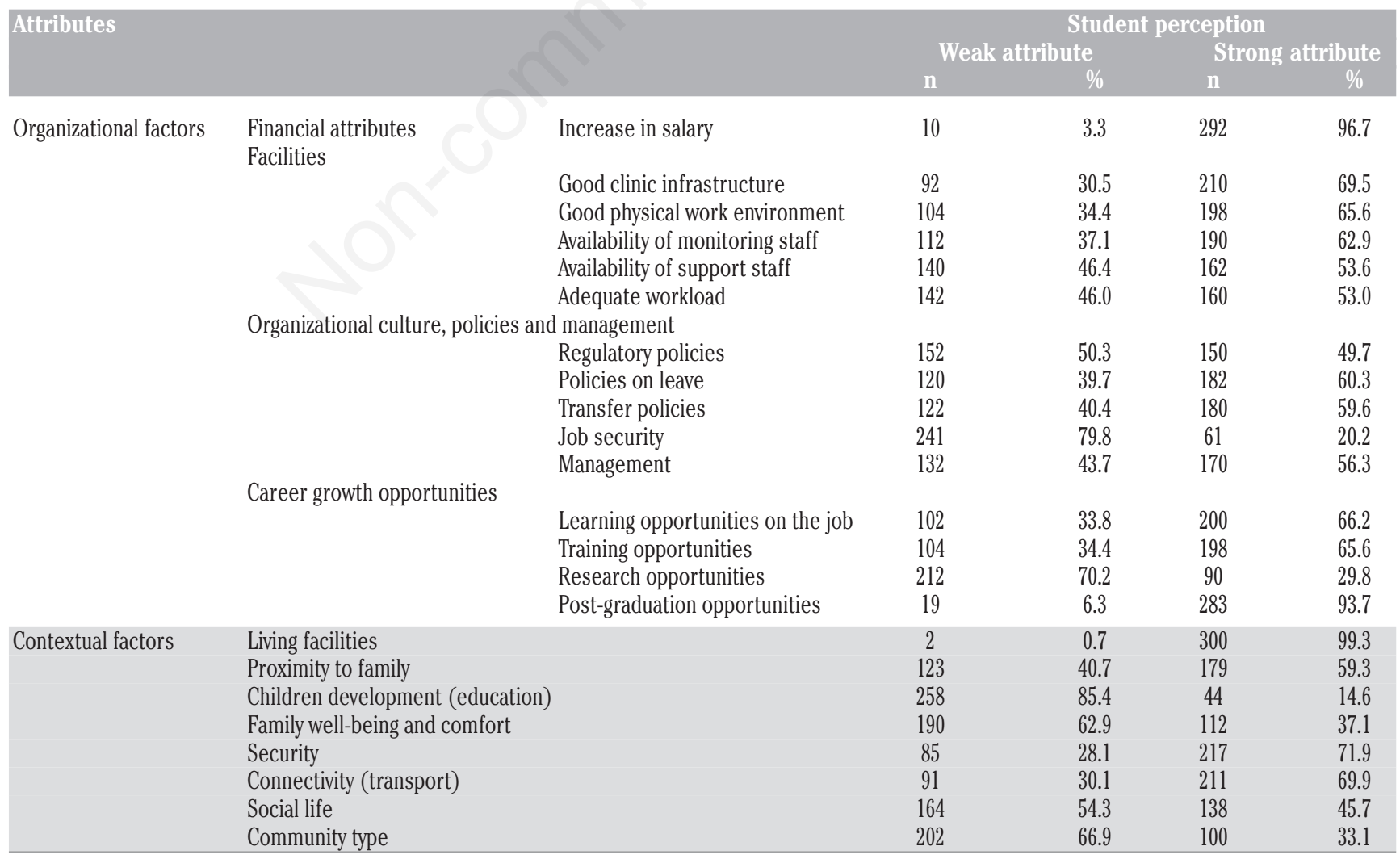

Categories are mutually exclusive. 
rural area. It was found that the students valued rural job attributes with appropriate salary, that enabled them to perform well clinically (improved infrastructure, physical work environment and monitoring staff), to grow professionally (career growth opportunities, especially for post-graduation), and that provided adequate living facilities, security and connectivity. This is consistent with what has emerged from focus group discussions with Ghana students, who expressed doubts about being able to apply their clinical skills to help patients in poorly equipped rural hospitals where basic inputs such as electricity and supply of medicines were unreliable. ${ }^{22}$

These findings are consistent with the results of studies in Ghana ${ }^{23}$ and Ethiopia ${ }^{12}$ in which housing facilities and security were scored as the most important determinants for accepting postings to rural areas. Moreover, in several case studies in middle- and low-income countries, supportive supervision has been noted to improve motivation among health workers to rural practice and quality of care. ${ }^{24-26}$ In Uganda, Kaye et al. found that a community based training experience of graduates significantly influenced their choice to work in a rural and underserved area, compared with their counterparts from the traditional curriculum. ${ }^{27} \mathrm{An}$ interesting experiment is under way in Zambia, where the government, with support from development partners, has instituted several measures to recruit and retain physicians in rural areas. Interventions included the refurbishment of government housing, school fees, car loans, improved hospital equipment and assistance with placement for post-graduate training at the end of a 3 -year contract. ${ }^{28}$

This study has certain implications. First, the majority of students have high intrinsic motivation for rural service. More research is needed to determine the potency of this motivation source in real-life decision making and how to best engage it in health policy. It is possible that emphasizing the community service aspect of medical practice and elevating the status of rural primary care in under-graduate and post-graduate training may help narrow the gap between motivation and eventual career choice in favor of rural areas. In addition, well-supervised and supported rural placements in which students experience the rewards of rural practice may help to persuade students who are largely unfamiliar with rural life. However, the success of these rural rotations is likely to depend heavily on having adequate local infrastructure and mentorship. ${ }^{17}$

Second, the current results suggest that effective strategies to promote and support rural practice after graduation should be implemented and evaluated. It was suggested that students may be willing to commit to short-term placements of 2 years or less in rural areas. ${ }^{29}$ The Ministry of Health may want to consider the possibility of short contracts that rotate physicians in and out of difficult staff rural areas.

\section{Conclusions}

A sizable portion of students reported high intrinsic motivation and therefore it is important to appeal and build on this in medical school curricula and in designing rural postings. However, extrinsic motivation and, perhaps most importantly, gender and socio-economic status, will likely continue to be important factors in deciding on job postings. The present research also suggests that increasing efforts to recruit medical students from low socio-economic backgrounds may be the most effective current pathway to increasing the yield of physicians willing to practice in underserved areas. Financial incentives from central or local governments would attract health workers to rural areas. Well planned strategies can help identify effective and efficient human and non-human resources for meeting the health needs of underserved rural populations in Alexandria.

\section{References}

1. World Health Organization. The world health report 2006: working together for health. Geneva: World Health Organization ed.; 2006.

2. Grobler L, Marais BJ, Mabunda SA, et al. Interventions for increasing the proportion of health professionals practicing in rural and other underserved areas. Cochrane Db Syst Rev 2009;1:CD005314.

3. Asante AD, Zwi AB. Factors influencing resource allocation decisions and equity in the health system of Ghana. Public Health 2009;123:371-7.

4. Nadeem N, Muhammed A. Brain drain: causes and implications. Karachi: DAWN; 2004.

5. Garbarino S, Lievens T, Quartey P, Serneels P. Ghana qualitative health worker study: draft report of preliminary descriptive findings. Accra: Oxford Policy Management Publ.; 2007.

6. United Nations Development Programme. Country fact sheets: Ghana. Geneva: UNDP ed.; 2009.

7. Anarfi JK. Migration expectations of trainee health professionals in Ghana. Accra: Institute of Statistical, Social and Economic Research and the University of Ghana Publ.; 2006.

8. Dussault G, Franceschini MC. Not enough there, too many here: understanding geo- graphical imbalances in the distribution of the health workforce. Hum Resour Health 2006;4:12.

9. Frey BS, Reto J. Motivation crowding theory: a survey of empirical evidence. J Econ Surv 2001;15:589-611.

10. Wilson NW, Couper ID, De Vries E, et al. A critical review of interventions to redress the inequitable distribution of healthcare professionals to rural and remote areas. Rural Remote Health 2009;9:1060.

11. Serneels P, Lindelow M, Montalvo JG, Barr A. For public service or money: understanding geographical imbalances in the health workforce. Health Policy Plann 2007;22:128-38.

12. Hanson K, Jack W. Health worker preferences for job attributes in Ethiopia: results from a discrete choice experiment (working paper). Washington, DC: Georgetown University Publ.; 2008.

13. Munga M, Mbilinyi D. Non-financial incentives and retention of health workers in Tanzania. Dar es Salaam: National Institute for Medical Research ed.; 2008.

14. Kuehn BM. Global shortage of health workers, brain drain stress developing countries. JAMA-J Am Med Assoc 2007;298: 1853-5.

15. Dovlo D. The brain drain and retention of health professionals in Africa. Accra: Medact ed.; 2003.

16. Akerlof GA. Labor contracts as partial gift exchange. Q J Econ 1982;97:543-69.

17. Ghana Ministry of Health. The Ghana health sector 2009 programme of work: change for better results: improving maternal and neonatal health. Accra: Ministry of Health Publ.; 2009.

18. Fritzen SA. Strategic management of the health workforce in developing countries: what have we learned? Hum Resour Health 2007;5:4.

19. Kletke PR, Marder WD, Silberger AB. The growing proportion of female physicians: implications for US physician supply. Am J Public Health 1990;80:300-4.

20. Knaul F, Frenk J, Aguilar A. The gender composition of the medical profession in Mexico: implications for employment patterns and physician labor supply. J Am Med Women Assoc 2000;55:32-5.

21. White CD, Willet K, Mitchell C, Constantine S. Making a difference: education and training retains and supports rural and remote doctors in Queensland. Rural Remote Health 2007;7:700.

22. Kruk ME, Johnson JC, Gyakobo M, et al. Rural practice preferences among medical students in Ghana: a discrete choice experiment. B World Health Organ 2010; 88:333-41.

23. Snow R, Asabir K, Mutumba M, et al. Policy talk: how Ghanaian doctors would improve 
retention in rural service. In: Proceedings of the Ghana Health Summit 2010: From Strategy to Action, 2009 Apr 26-30, Accra, Ghana.

24. Hole AR. Modelling heterogeneity in patients' preferences for the attributes of a general practitioner appointment. J Health Econ 2008;27:1078-94.

25. Loevinsohn BP, Guerrero ET, Gregorio SP. Improving primary health care through systematic supervision: a controlled field trial. Health Policy Plann 1995;10:144-53.

26. Bosch-Capblanch X, Garner P. Primary health care supervision in developing countries. Trop Med Int Health 2008;13:369-83.

27. Douglas M. Supervision of rural health centres in Papua New Guinea: consolidation of the delivery of health services. Papua New Guinea Med 1991;34:144-8.
28. Kaye DK, Mwanika A, Sewankambo N. Influence of the training experience of Makerere University medical and nursing graduates on willingness and competence to work in rural health facilities. Rural Remote Health 2010;10:1372.

29. Koot J, Martineau T. Mid term review. Zambian health workers retention scheme (ZHWRS) 2003-2004. Lusaka: Ministry of Health Publ.; 2005. 